\title{
The Autosomal Dominant Facioscapuloperoneal Muscular Dystrophy with 4q35 Chromosomal Deletion in Two Russian Families
}

Kazakov V ${ }^{1 *}$, Rudenko $D^{1}$, Kolynin $\mathbf{V}^{1}$ and Pozdnyakov $\mathrm{A}^{2}$

${ }^{1}$ Department of Neurology, Pavlov State Medical University, St. Petersburg, Russia

${ }^{2}$ Institute of Radiology, St. Petersburg, Russia

\begin{abstract}
We give the description of the pattern of muscle affections in two autosomal dominant 4q35-linked facioscapuloperoneal muscular dystrophy (FSPMD) families in which the patients were re-examined by V.K. in 24 28 and 35 - 37 years after their first examination. The disease started with initial involvement of facial and shoulder girdle muscles and in some time later of the peroneal group (anterior tibial) of muscles became involved. However, in two probands the dystrophic process gradually extended to the thighs (posterior group of muscles, namely), pelvic girdle (gluteus maximus muscles, namely) and the upper arm (biceps brachii muscles were slightly affected) and in three their relatives with clinical facioscapuloperoneal (FSP) phenotype the severe involvement of some posterior thigh muscles during MRI study was revealed. In this connection, the term "facioscapulolimb muscular dystrophy, type 2 (FSLD2), a descending type with a "jump" with initial FSP phenotype" would be more correct instead of the name facioscapuloperoneal muscular dystrophy. The FSP phenotype constitutes merely a stage in the development of FSLD2. The CT and MRI pattern of muscle involvement does not fully correlate with clinical pattern of muscle affection. We suppose that classical AD FSPMD is an independent clinical form which is different from the classical FSHD although both of them are connected with $4 q 35$ chromosomal deletion.
\end{abstract}

Keywords: Facioscapuloperoneal muscular dystrophy; Facioscapulohumeral dystrophy; Clinical heterogeneity

Abbreviations: Ph: Phenotypes; FS: Facioscapular; FSH: Facioscapulohumeral; FSP: Facioscapuloperoneal; FSPF: FacioScapulo-Peroneal-Femoral; FSPFGH: Facio-Scapulo-Peroneal-Femoro (Posterior Group of the Muscles) -Gluteo (Gluteus Maximus)-Humeral (Biceps Brachii); FSLD1: Facioscapulolimb Muscular Dystrophy, Type 1, a Gradually Descending with Initial FSH Phenotype; FSLD2: Facioscapulolimb Muscular Dystrophy, Type 2, a Descending with a "Jump" with Initial FSP Phenotype; FSHD: Facioscapulohumeral Muscular Dystrophy; FSPMD: Facioscapuloperoneal Muscular Dystrophy; SPD: Scapuloperoneal Muscular Dystrophy; (F): Minimal or Slight Affection of the Isolated Facial Muscles or their Parts; $(\mathrm{H})$ : Slight Affection (Grade 4) Biceps Brachii Muscle; (S) : Asymptomatic Atrophy and Weakness of the Lower and Middle Parts of Trapezius Muscle; (FG): Slight Affection (Grade 4) of Posterior Group of Thigh Muscles and Gluteus Maximus; Pr : Presymptomatic; № F: Number of Family; DFS : DNA Fragment Size; Kb: Kilobases; CH : Data From Case History

\section{Introduction}

Facioscapulohumeral muscular dystrophy (FSHD) is an autosomaldominant disease characterized by gradually descending distribution of muscle weakness with successive involvement of the face, shoulder girdle, upper arm, trunk, pelvic girdle, and thigh and later lowers leg muscles. The disease is associated with DNA deletions resulting in the decrease of size of p13E-11 EcoRi DNA fragment size less than $38 \mathrm{~kb}$. in chromosome 4q35. A normal number of repeat units vary from 41 to $350 \mathrm{~kb}$. Some authors suppose that scapuloperoneal muscular dystrophy (SPD) with or without involvement of facial muscles is probably a variant of facioscapulohumeral muscular dystrophy (FSHD) [1-9]. Others suppose that SPD is probably an independent form of the disease [10-17]. Many patients with SPD have a minimal or very mild weakness or atrophy of isolated facial muscles or even of only small their parts which they have never noted and had had no complaints. That is why some neurologists didn't include this sign in the name of the disease. It is not clear what degree of affection of isolated facial muscles must be in the SPD patient is order to add the word "facio" to the name "scapuloperoneal"? The opinion exists that in SPD patients the arm (humeral) muscle are involved in the process only after the facial and shoulder girdle muscles become affected. Thus, these patients are presented by FSH phenotype but not FSP one at the early stage of the disease. It is unclear when biceps brachii muscles are involved in patient with SPD: is it before or after an affection of the lower limb muscles? In the recent years, several studies have reported the value of CT and MRI in identifying patterns of muscle involvement in FSHD [18-21]. However, it is not clear as what are the CT and MRI findings for lower limb muscles are present in facioscapuloperoneal muscular dystrophy (FSPMD) patients.

\section{Aim}

To establish the clinical, CT and MRI phenotypes of muscle involvement at the FSPMD in two Russian families in which the patients were re-examined by V.K. in $24-28$ and $35-37$ years after the first examination.

\section{Methods}

We examined of six patients from two autosomal dominant families with 4q35-linked FSPMD. To reveal the sequence of muscle involvement and establish the time of appearance of dysfunction of separate muscles and muscle groups a special test questionnaire was used [22]. Muscle strength of 66 muscle pairs and muscle groups including the isolated portions of some muscles was measured manually according to Daniels et al. [23] using a 10-grade scale. The examination of the tropics and

*Corresponding author: Valery Kazakov, Professor of Clinical Neurology, Department of Neurology, Pavlov State Medical University, L. Tolstoy Str. 6/8, 197022 St. Petersburg, Russia; Tel: +7 812 323-21-21; Fax: +7812 5132612; E-mail: valerykazakov@mail.ru

Received March 23, 2013; Accepted May 07, 2013; Published May 20, 2013

Citation: Kazakov V, Rudenko D, Kolynin V, Pozdnyakov A (2013) The Autosomal Dominant Facioscapuloperoneal Muscular Dystrophy with 4q35 Chromosomal Deletion in Two Russian Families. Hereditary Genetics S1: 007. doi:10.4172/2161. 1041.S1-007

Copyright: @ 2013 Kazakov V, et al. This is an open-access article distributed under the terms of the Creative Commons Attribution License, which permits unrestricted use, distribution, and reproduction in any medium, provided the original author and source are credited. 
function of the muscles, and abnormal postures of separate segments of limbs and the body were conducted according to Kendall and Kendall [24]. Mimic muscle strength, degree severity of the disease and dailylife work disability were measured according to the criteria compiled by Kazakov [25,26]. In all the patients the Southern blot of DNA analysis was carried out by EcoRI/BlnI double digestion using the $4 \mathrm{q} 35$ probe p13E-11 (D4F104S1) and other 4q35 markers (D4S139,D4S153) and the conventional linear gel electrophoresis which was fulfilled at the Department of Neuromuscular Research, National Institute of Neuroscience, NCNP, Tokyo, Japan [27]. The needle EMG (the biceps brachii, vastus lateralis and anterior tibial muscles) and motor and sensory nerves (the ulnar, peroneal, radial superficial and sural nerves) conduction velocity investigations on the both sides were performed by electromyograph ("Viking IV", Nicolet, USA). Computed tomography (CT) of lower limb muscles was performed bilaterally in the mid-sections of the thigh and lower leg at computer tomographic scanner (Siemens, Somaton, Germany) with axial $5 \mathrm{~mm}$ thick slices. Abnormal signal was classified according to Hawley et al. [18]. Magnetic resonance imaging (MRI) of 20 muscles bilaterally was performed at a 1.5-tesla Siemens; Magneton Vision system using axial T1 weighted (T1W) images. Twenty muscle sections were analyzed with an emphasis on the midsections of the thighs and lower legs. Abnormal signal was classified according to Jungbluth et al. [28].

\section{Results}

In the first family (Table 1, DNA fragment size 27/24 kb, Figure 1) the female proband at the age of 36 presented a "pure" and severe scapuloperoneal phenotype with minimal affection of orbicularis oris muscle on the left side which transferred into final facio-scapuloperoneal-femoro (posterior thigh muscles, namely but not quadriceps)gluteo (gluteus maximus, namely but not gluteus medius)-(humeral; biceps brachii slightly weakened on the left side only) [FSPFG(H)] phenotype at the age of 73 which was revealed during her reexamination after 37 years (Figures 3a-3i).

EMG in all examined muscles (methods) showed no abnormal insertion and spontaneous activity. On minimal voluntary effort a high recruital of short-duration and low-amplitude of motor unit action potential (MUAPs) and increased number of polyphasic potentials were present. During mild and maximum contraction a complete interference pattern in biceps brachii and vastus lateralis with EMG amplitude until 1,5 - $2 \mathrm{mV}$ was revealed. In tibialis anterior muscles the EMG interference pattern was slightly reduced with amplitude $0.7 \mathrm{mV}$. Sensory conduction velocity (SCV) and sensory responses

\begin{tabular}{|c|c|c|c|c|c|}
\hline $\begin{array}{c}\text { № F., } \\
\text { DFS, Kb }\end{array}$ & Members & $\begin{array}{c}\text { Age onset } \\
\text { Year }\end{array}$ & $\begin{array}{l}\text { Age exam } \\
\text { year }\end{array}$ & $\begin{array}{c}\text { Year Exam } \\
\text { year }\end{array}$ & Phenotypes \\
\hline \multirow{11}{*}{$\begin{array}{c}F .2 \\
27 / 24\end{array}$} & \multirow{4}{*}{ Proband } & \multirow{4}{*}{$6-10$} & $36 \mathrm{ch}$ & 1960 & (F)SP \\
\hline & & & 45 & 1969 & $(F) S P(F G)$ \\
\hline & & & 69 & 1993 & FSPFG(H) \\
\hline & & & 73 & 1997 & FSPFG(H) \\
\hline & \multirow{4}{*}{$\begin{array}{c}\text { Proband's } \\
\text { brother }\end{array}$} & \multirow{4}{*}{$6-10$} & 36 & 1969 & (F)SP \\
\hline & & & 60 & 1993 & (F)SP \\
\hline & & & 64 & 1997 & $(F) S P$ \\
\hline & & & 73 & 2005 & (F)SP \\
\hline & \multirow{3}{*}{$\begin{array}{c}\text { Proband's } \\
\text { niece }\end{array}$} & \multirow{3}{*}{$<5$} & 6 & 1969 & $F(S)$ \\
\hline & & & 30 & 1993 & FSP \\
\hline & & & 42 & 2005 & FSP \\
\hline
\end{tabular}

Table 1: Family 2. Age of onset of the disease, age and year of examination and re-examination, phenotypes (the static and dynamic muscle patterns) in patients from the family 2 with $4 q$ 35-linked AD FSPMD.

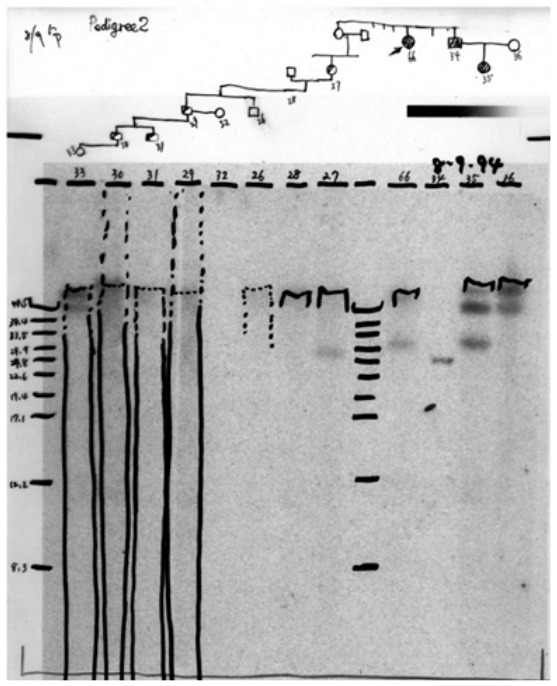

Figure 1: Southern blot of EcoRl-digested genomic DNA in family 2, using probe p13E-11. In proband (№ 66), proband's brother (№ 34) and proband's niece (№ 35) the EcoRI fragment sizes of $37 \mathrm{~kb}$ were revealed, respectively. In presymptomatic proband's relatives (№ $27,29,30,31$ ) as well as in other proband's relatives (№ $26,28,32,33,36$ ) the EcoRI fragment sizes more than $50 \mathrm{~kb}$ were found.

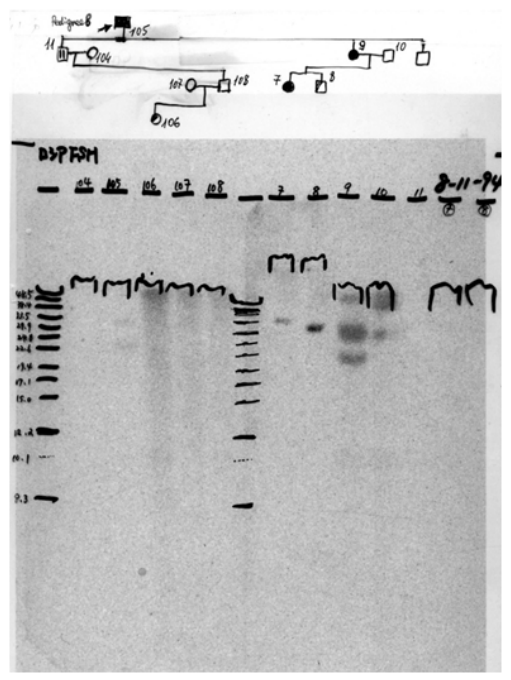

Figure 2: Southern blot of EcoRI-digested genomic DNA in Family 8, using probe p13E-11. In proband (№ 105), proband's daughter (№ 9) and proband's granddaughter (№ 7) the EcoRI fragment sizes of $23 \mathrm{~kb}$ were revealed, respectively. In presymptomatic proband's grandson (№ 8) and greatgranddaughter (№ 106) as well as in other proband's relatives (№ 10. 11. 104. $107,108)$ the EcoRI fragment sizes more than $50 \mathrm{~kb}$ were found.

in sural and radial superficial nerves was normal. Motor conduction velocity (MCV) in ulnar and peroneal nerves was in normal limits with slightly decreased amplitude in legs $(1.5 \mathrm{mV})$. EMG revealed myopathic changes.

Thus, in this patient the severe scapuloperoneal phenotype with a very mild weakness of the orbicularis oris muscle was present within the clinical picture for about 10 years and then it gradually passed into final FSPFG $(\mathrm{H})$ phenotype with severe weakness of the upper part of orbicularis oris muscle. The patient worked as an engineer until the age of 55 (the pension time) and continued working after that. At the age of 80 (January 2005) she can climb up stairs for the $4^{\text {th }}$ floor with aid of 
railing, she can walk independently for a short distance but cannot use city transport.

The proband's brother (Table 1), at the age of 36 and during his re-examination after 37 years when he was 73 y.o. presented the same of "pure" and severe scapuloperoneal phenotype with mild atrophy of upper lip on the right side and very slight weakness of orbicularis oculi muscles. However, the MRI of his lower limb muscles revealed the severe involvement of some posterior thigh muscles and rectus femoris (Figures $4 \mathrm{a}-4 \mathrm{~m})$. Thus in this patient the severe scapuloperoneal phenotype with a very slight weakness of some facial muscles has existed in the clinical picture for more than 36 years. The patient worked as a driver until the age of 60 (the pension time) and continued working after that. At the age of 73 (December 2005), he can walk independently and use city transport.

The proband's niece (Table 1) at the age of 6 was presymptomatic (Pr) with a facio (scapular) $[\mathrm{F}(\mathrm{S})]$ phenotype which transferred into pure and moderate facioscapuloperoneal (FSP) phenotype with severe affection orbicularis oris and orbicularis oculi muscles at the age of 42 which was revealed during here-examination after 36 years. However, the MRI of her lower limb muscles showed the severe involvement of posterior thigh muscles and rectus femoris (Figures $5 \mathrm{a}-5 \mathrm{k}$ ). Thus, in this patient the scapuloperoneal phenotype with severe weakness of some facial muscles was present in clinical picture of the disease for more than 12 years. Now the patient works as an engineer and can walk and use city transport.

In the second family (Table 2, DNA fragment size $23 / 20 \mathrm{~kb}$, Figure 2) the man proband 60 y.o. presented a "pure" and severe scapuloperoneal phenotype with minimal weakness of the orbicularis oculi muscles which transferred into final FSPFG $(\mathrm{H})$ phenotype with slight affection of biceps brachii muscle on the left side at the age of 88 which was revealed during his re-examination after 28 years (Figures 6a-6f).

EMG showed no abnormal insertion and spontaneous activity in examined muscles. In all muscles on minimal contraction a high
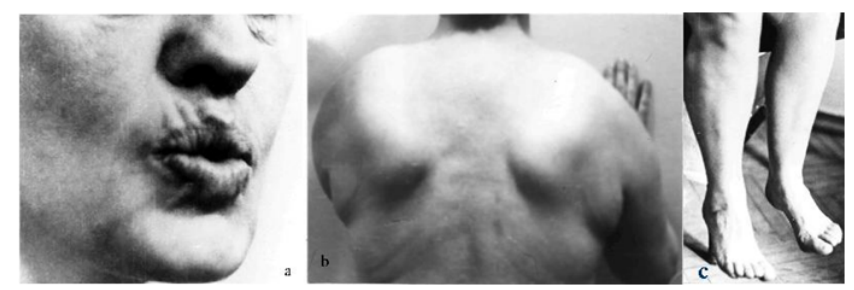

Figures 3a-3c: Observation 7, pedigree 2, proband, aged 45.

Very slight weakness of the orbicularis oris muscle on the left side (a), the winging of the scapulae (b),

The patient cannot extend her feet is seen more clearly on the right side (c).
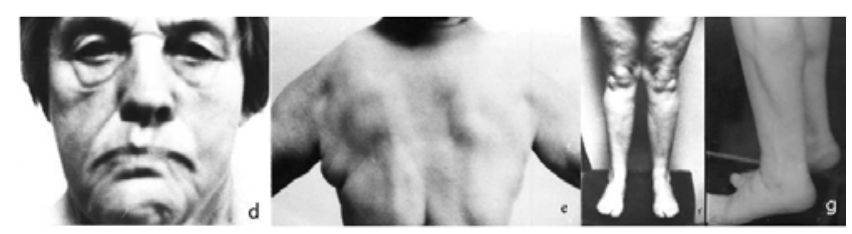

Figures 3d-3g: The same patient as in Figure 3 a- c, aged 69. Re-examination in 24 years after the first examination.

The patient cannot to puff out the cheeks (d), abduct her arms to the horizontal level (e)

And stand up on the heels (f) but can stand up on her toes with difficulty (g).

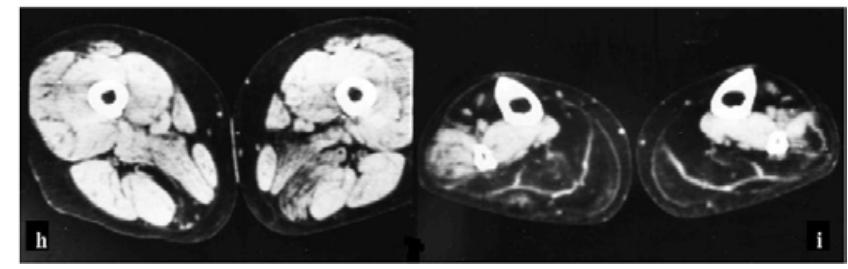

Figure 3h and 3i: The same patient as in Figure 3a-3g, aged 71. Muscle CT of the lower limbs: in the mid- lower legs

(i) Showed a total involvement of the tibialis anterior, extensor digitorum longus, extensor halluces longus, soleus and gastrocnemius on the both sides with sparing of peroneus longus on the right side and deep posterior compartment of lower leg muscles; in the mid- thighs (h) showed total/severe affection of semimembranosus is seen more clearly on the right side and a less degree of adductor magnus and adductor longus is seen more clearly on the left side with sparing quadriceps, biceps, semitendinosus, gracilis and sartorius, Note: R-right, L-left

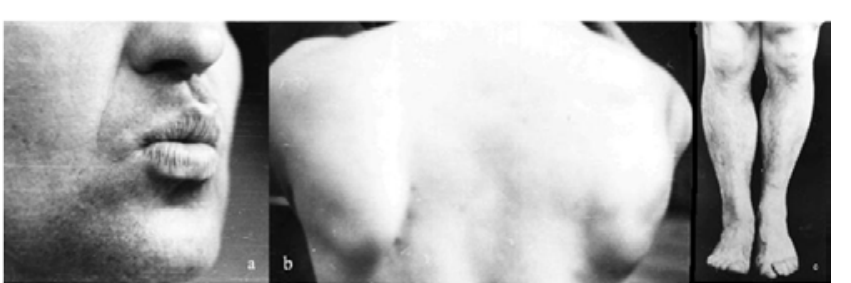

Figures 4a-4c: Observation 8, family 2, proband's brother, aged 36. Minimal atrophy of the upper lip on the right side (a), the scapulae sharply displacement outwards and forwards (b), inability to stand up on the heels is seen more clearly the left side (c)

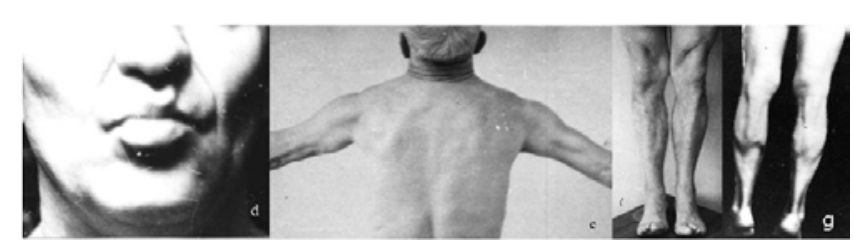

Figures 4d-4g: The same patient as in Figure 4a-4c aged 60. Re-examination in 24 years after the first examination. Asymmetry of the lips when puckering them to whistle (d), severe weakness of the trapezius and serratus anterior muscles (e), inability to stand up on the heels is seen more clearly on the left side (f), the patient can stand up on his toes $(\mathrm{g})$.

recruital of MUAPs was found. Most of MUAPs were decreased in amplitude and duration. On mild and maximal contraction in proximal muscles a complete interference pattern was revealed. In tibialis anterior muscles an interference pattern was slightly reduced with amplitude 0.9 $\mathrm{mV}$. MCV (the ulnar and peroneal nerves) and SCV (the superficial radial and sural nerves) in upper and lower limbs were in normal limits. EMG revealed myopathic changes.

Thus, in this patient the severe scapuloperoneal phenotype with very slight weakness of orbicularis oculi muscles predominated in the clinical picture for a long period of time and then gradually passed into final FSPFG $(\mathrm{H})$ phenotype with severe weakness of the orbital part of orbicularis oculi muscles. The patient worked as a sales manager untill the age of 60 (the pension time) and continued working after that. At the age of 88 he did not use a wheelchair and could walk with aid of a stick only for a short distance. He died at the age of 88 after acute ischemic stroke.

The proband's daughter (Table 2), at the age 28 and in 27 years during her re-examination at the age of 55 presented the same mild (F) 
Citation: Kazakov V, Rudenko D, Kolynin V, Pozdnyakov A (2013) The Autosomal Dominant Facioscapuloperoneal Muscular Dystrophy with 4q35 Chromosomal Deletion in Two Russian Families. Hereditary Genetics S1: 007. doi:10.4172/2161-1041.S1-007

SP phenotype. The patient did not admit her motor disturbances and supposed that she was healthy. Molecular analysis revealed a DFS 23/20 $\mathrm{kb}$ deletion upon double digestion.

The proband's granddaughter (Table 2) at the age of 5.5 was presymptomatic with facio (scapular) $[\mathrm{F}(\mathrm{S})]$ phenotype. During her re-examination after 24 years at the age of 29 she presented a "pure" and severe FSP phenotype with severe affection of facial muscles which transferred into FSP (F) phenotype with mild affection of posterior thigh muscles at the age of 41 which was revealed during her re-examination after 35 years. However, on MRI of her lower limb muscles the total involvement of posterior thigh muscles was found (Figures $7 \mathrm{a}-7 \mathrm{~m}$ ). Thus, in this patient the scapuloperoneal phenotype with severe weakness of the some facial muscles existed in the clinical picture for about 12 years and then passed into FSP (F) phenotype. Now the patient works as a computer programmer, and she can walk and use city transport.

\begin{tabular}{|c|c|c|c|c|c|}
\hline $\begin{array}{c}\text { № F., DFS, } \\
\text { Kb }\end{array}$ & Members & $\begin{array}{l}\text { Age onset } \\
\text { Year }\end{array}$ & $\begin{array}{c}\text { Age exam } \\
\text { year }\end{array}$ & $\begin{array}{l}\text { Year Exam } \\
\text { year }\end{array}$ & Phenotypes \\
\hline \multirow{10}{*}{$\begin{array}{c}F .2 \\
23 / 20\end{array}$} & \multirow{3}{*}{ Proband } & \multirow{3}{*}{$6-10$} & 60 & 1969 & (F)SP \\
\hline & & & 86 & 1994 & FSPFG(H) \\
\hline & & & 88 & 1996 & FSPFG(H) \\
\hline & \multirow{3}{*}{$\begin{array}{l}\text { Proband's } \\
\text { daughter }\end{array}$} & \multirow{3}{*}{$?$} & 28 & 1969 & (F)SP \\
\hline & & & 52 & 1993 & $(\mathrm{~F}) \mathrm{SP}$ \\
\hline & & & 55 & 1996 & $(F) S P$ \\
\hline & \multirow{4}{*}{$\begin{array}{c}\text { Proband's } \\
\text { Grand } \\
\text { daughter }\end{array}$} & \multirow{4}{*}{$<5$} & 5.5 & 1969 & $\mathrm{~F}(\mathrm{~S})$ \\
\hline & & & 29 & 1993 & FSP \\
\hline & & & 33 & 1996 & FSP \\
\hline & & & 41 & 2004 & $\mathrm{FSP}(\mathrm{F})$ \\
\hline
\end{tabular}

Table 2: Family 8. Age of onset of the disease, age and year of examination and reexamination, phenotypes (the static and dynamic muscle patterns) in patients from the family 8 with $4 q 35$-linked AD FSPMD.

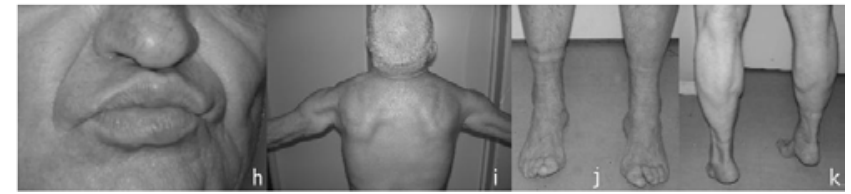

Figures 4h-4k: The same patient as in Figure 4a-g, aged 73. Re-examination in 37 years after the first examination. Slight atrophy of the upper lip on the right side (h), the patient cannot abduct arms to the horizontal level (i) and stand up on his heels (j) but can stand up on his toes $(\mathrm{k})$.

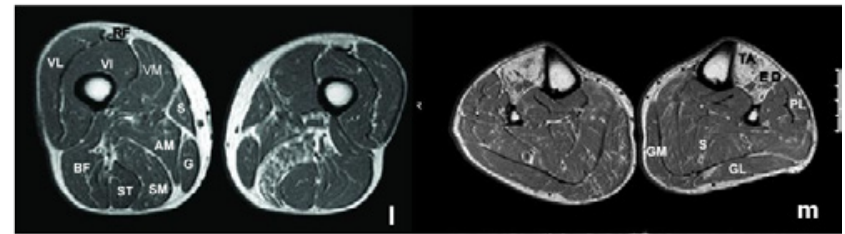

Figure $4 \mathrm{I}$ and $4 \mathrm{~m}$ : The same patient as in Figure 4a-k, aged 73 . Muscle MRI axial T1W images of the lower limbs:

in the mid-lower legs $(\mathrm{m})$ showed a severe affection of tibialis anterior, extensor digitorum longus and a less degree of extensor hallucis longus and slight involvement of gastrocnemius (medial head) and soleus on the right side with sparing of peroneus longus and deep posterior compartment of lower leg muscles; in the mid-thighs (I) Showed a severe involvement of semimembranosus and a lesser degree of adductor magnus on the left side with sparing of quadriceps, except rectus femoris, and with sparing semitendinosus, biceps, gracilis and sartorius. Note: RF- $m$. rectus femoris, VL- $m$. vastus lateralis, VM- $m$. vastus medialis, VI- $\mathrm{m}$. vastus intermedius, AM- $\mathrm{m}$. adductor magnus, BF- $\mathrm{m}$. biceps femoris, ST- $m$. semitendinosus, SM- $m$. semimembranosus, $S-m$. sartorius, G- $m$. gracilis, TA- m. tibialis anterior, ED- m. extensor digitorum longus, PL$\mathrm{m}$. peroneus longus, $\mathrm{S}-\mathrm{m}$. soleus, GM- $\mathrm{m}$. gastrocnemius medialis, GL- $\mathrm{m}$. gastrocnemius lateralis. R-right, L-left

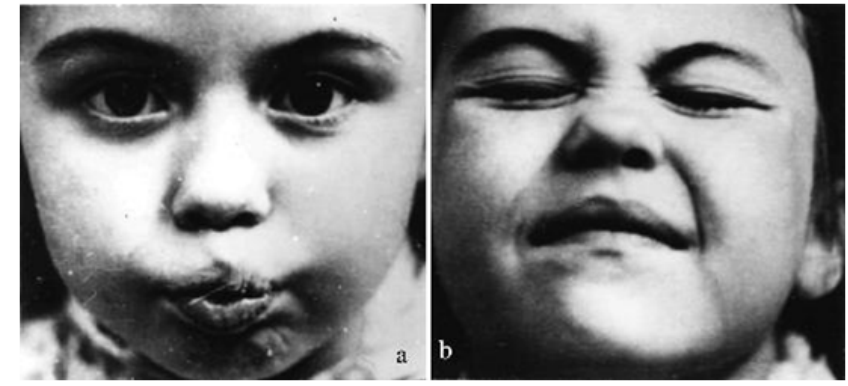

Figure $\mathbf{5 a}$ and $\mathbf{5 b}$ : Observation 11 , family 2 , the proband's niece, aged 6 . Very slight weakness of orbicularis oris on the right side; (a), severe weakness of the orbital parts of the orbicularis oculi muscles (b)

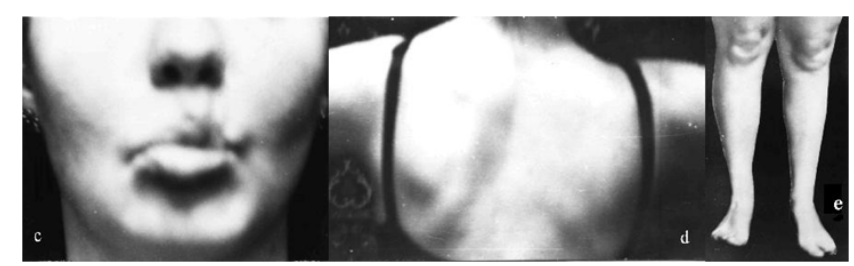

Figure 5c-5e: The same patient as in Figure $5 a$ and $5 b$, aged 30 . Re-examination in 24 years after the first examination. Severe weakness and atrophy of the upper part of orbicularis oris muscle on the right side (c), the scapulae recede from the chest is seen more clearly on the left side (d), inability to stand up on the heels is seen more clearly on the left side (e).

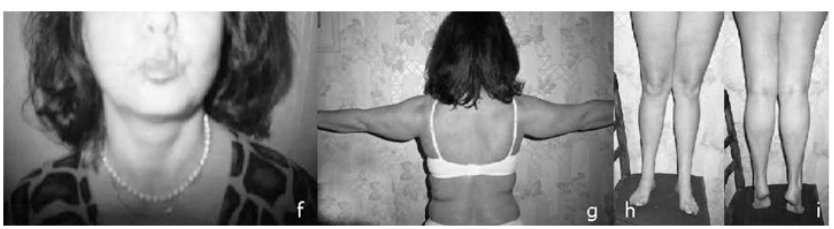

Figures 5f-5i: The same patient as in Figures 5a-5e, aged 42. Re-examination in 36 years after the first examination. The patient cannot pucker lips to whistle (f), abduct arms to the vertical level $(\mathrm{g})$ and stand up on her heels ( $\mathrm{h}$ ) but can stand up on her toes (i).

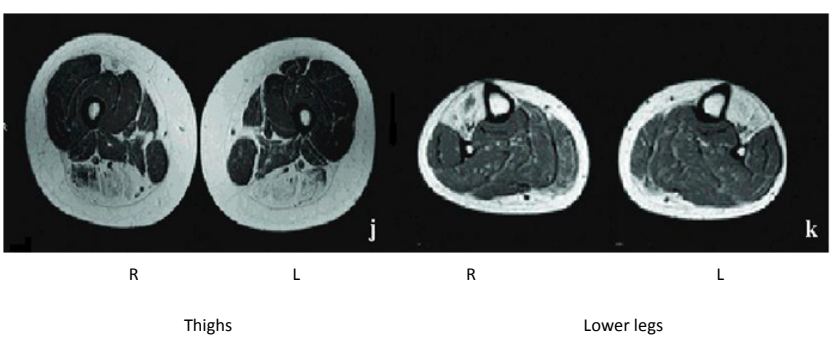

Figure $\mathbf{5 j}$ and $\mathbf{5 k}$ : The same patient as in Figures 5c-5i, aged 42. Muscle MRI axial T1W images of the lower limbs:

In the mid-lower legs (k) showed a severe/total involvement of tibialis anterior, extensor digitorum

Longus, extensor hallucis longus and a moderate affection of gastrocnemius (medial head) and a less

Degree of soleus is seen more clearly on the right side with sparing of peroneus longus and deep

Posterior compartment of lower leg muscles; in the mid-thighs (j) showed a total/ severe affection of

Semimembranosus and semitendinosus is seen more clearly on the left side and a lesser degree of

Biceps (long heads) and adductor longus with sparing of quadriceps, except of rectus femoris on

The right side, and with sparing of adductor magnus, gracilis and sartoris. 


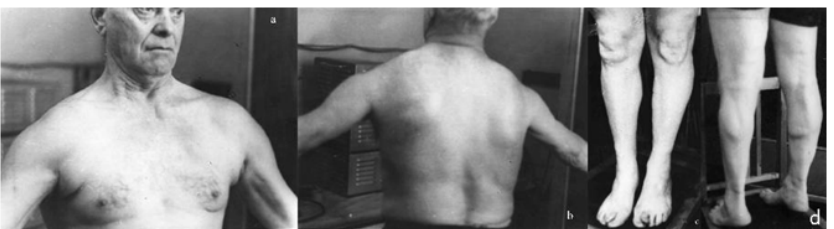

Figures 6a-6d: Observation 32, pedigree 8 , the proband aged 60 . Severe atrophy of the left pectoralis major muscle, especially of its sternocostal part and partly clavicular one; displacement of the shoulder girdle downwards and forwards (a), the patient cannot abduct his arms to the horizontal level (b) and stand up on the heels (c) but can stand up on the toes; preservation of muscle bulk in thighs $(\mathrm{d})$.

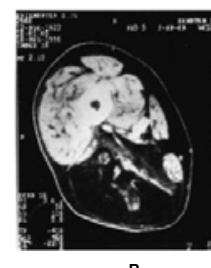

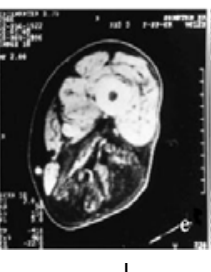

Thighs

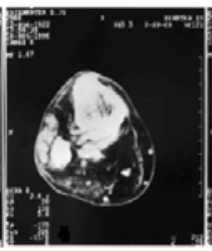

$\mathrm{R}$

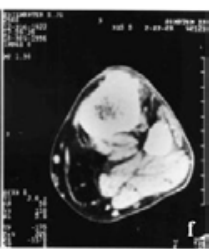

L
Figure 6e and 6f: The same patient as in Figures $6 a-6 d$ at the age of 88 . Reexamination in 28 years after the first examination.

Muscle CT of the lower limbs: in the mid-lower legs (f) showed total/severe involvement of the tibialis anterior, extensor hallucis longus and extensor digitorum longus (partly), soleus and gastrocnemius (especially a medial heads) is seen more clearly on the right side with sparing of peroneus longus, tibialis posterior and flexor digitorum longus especially on the left side; in the mid-thighs (e) showed a total/severe involvement of adductor magnus, adductor longus, biceps (both heads), semitendinosus, semimebranosus is seen more clearly on the right side with relative sparing of the quadriceps (slightly moth-eaten appearance), sartorius and gracilis.

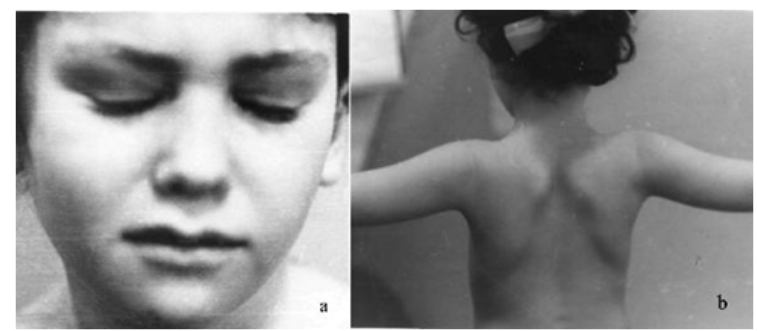

Figure 7a and 7b: Observation 33, pedigree 8, proband's granddaughter, aged 5.5. No function of the orbital parts of the orbicularis oculi muscles. «A crying-like face» is the sign of the weakness of the orbicularis oris muscle (a); slight atrophy of the middle and lower parts of trapezius muscles (b).

\section{Conclusion}

In the observed members of these two families the disease began with initial involvement of facial and shoulder girdle muscles and in some time later the lesion of peroneal group (anterior tibial) muscles adjoined. However, in two probands the dystrophic process gradually extended to the thighs (posterior group of muscles, namely; the quadriceps muscles were preserved), pelvic girdle (gluteus maximus muscles, namely; the gluteus medius muscles were preserved)) and upper arm (biceps brachii were slightly weakened on the one side only) and in three their relatives clinically presented by facioscapuloperoneal (FSP) phenotype the severe involvement of some posterior thigh muscles during MRI study was revealed. In this connection, the term "facioscapulolimb muscular dystrophy, type 2 (FSLD2), a descending type with a "jump" with initial FSP phenotype" instead of the name facioscapuloperoneal

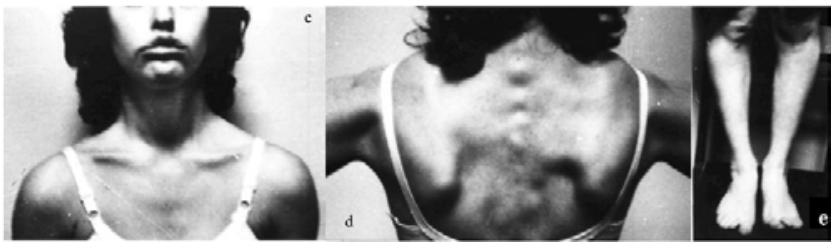

Figures 7c-7e: The same patient as in Figure $7 a$ and $7 b$ aged 29. Reexamination in 24 years after the first examination. Inability to pucker lips to whistle; severe atrophy of the sternocostal portions of pectoralis major muscles on both sides (c), severe involvement of the middle and lower parts of trapezius muscles (d), inability to stand up on the heels (e).

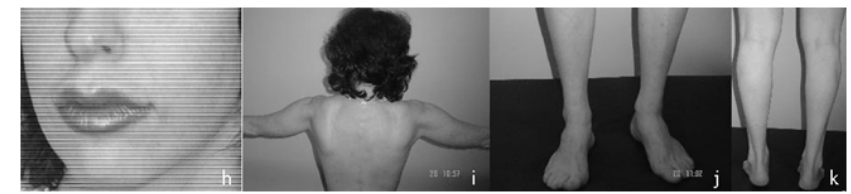

Figures 7h-7k: The same patient as in Figures $7 a-7 e$ at the age of 41 . Reexamination in 35 years after the first examination. The patient could not stretch out the lips (h), abduct arms above the horizontal level (i) and stand up on her heels (j) and toes (k).

muscular dystrophy would be more correct. These data show that FSLD2 is a very special type of MD with a "hard" static and dynamic pattern of muscle involvement which is due to action of special basic gene located on chromosome $4 \mathrm{q} 35$. The scapuloperoneal phenotype with slight or severe affection of the isolated facial muscles or their parts (and it is more correctly to call it the FSP phenotype) constitutes merely a stage in the development of FSLD2. Muscle CT and MRI of the observed patients showed more often and severe involvement of tibialis anterior, extensor digitorum longus and extensor hallucis longus, semimembranosus, long head of biceps femoris, semitendinosus, rectus femoris and sometime later of adductors of thighs and gastrocnemius (medial heads) and less degree soleus with sparing of peroneus longus and deep posterior compartment of lower leg, quadriceps (except of rectus femoris), gracilis and sartorius muscles.

The radiological muscle pattern does not fully correlate with the clinical pattern of muscle weakness. In patients with FSP phenotype the posterior of thigh muscles together with quadriceps muscles clinically were not affected (carried normal strength) although during MRI and CT studies total/severe involvement of some hamstrings was revealed in 3 men and rectus femoris lesion in 2 ones.

We observed the same clinical picture with stereotype pattern of muscle involvement at the different stages of the diseases in 28 FSLD2 patients from 14 autosomal dominant families who were re-examined (V.K.) in 27-49 years after their first examination [29,30]. We suppose that this similar clinical picture in observed patients was due to action of the specific basic gene located on chromosome $4 \mathrm{q} 35$.

Thus, our present clinical, CT and MRI study data, as well as our more early investigations, show that the facioscapuloperoneal muscular dystrophy (or FSLD2, a descending type with a "jump" with initial FSP phenotype - author's note) is probably an independent form of muscular dystrophy which is different from classical FSHD (or FSLD1, a gradually descending type with initial FSH phenotype - author's note) $[22,25,26,29-34]$. It is possible that that these disorders are connected with the various $4 \mathrm{q} 35$ chromosomal mutations. 
Citation: Kazakov V, Rudenko D, Kolynin V, Pozdnyakov A (2013) The Autosomal Dominant Facioscapuloperoneal Muscular Dystrophy with 4q35 Chromosomal Deletion in Two Russian Families. Hereditary Genetics S1: 007. doi:10.4172/2161-1041.S1-007

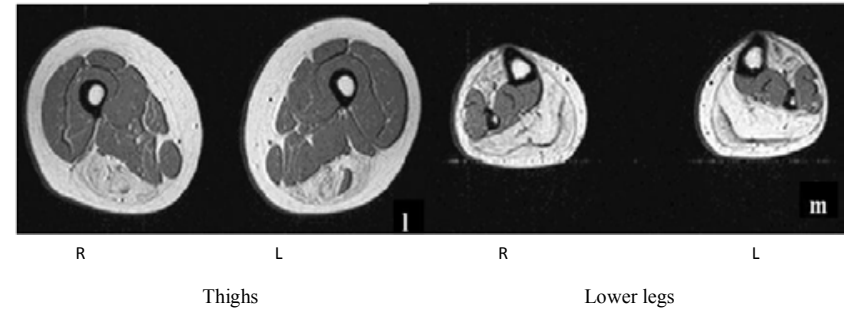

Figure $7 \mathrm{I}$ and $7 \mathrm{~m}$ : The same patient as a Figures $7 \mathrm{a}-7 \mathrm{~g}$ at the age of 41 . Muscle MRI axial T1W images of the lower limbs: in the mid-lower legs $(\mathrm{m})$ showed total affection of the anterior and superficial posterior compartments of lower leg muscles with sparing of peroneus longus and deep posterior compartment of lower leg muscles; in the mid-thighs (I) showed total/severe affection of hamstrings with sparing of quadriceps, adductors, gracilis and sartorius.

\section{Acknowledgment}

The authors are grateful to Drs. K. Arahata ${ }^{\dagger}$ and H. Sugita and Ms. K. Goto for molecular genetic testing of the DNA samples, and to the Japanese Research Fund and Japan Foundation for Aging and Health for the support of this study.

\section{References}

1. Ricker K, Mertens HG (1968) The differential diagnosis of the myogenic (facio)scapulo-peroneal syndrome. Eur Neurol 1: 275-307.

2. Serratrice G, Roux H, Aquaron R, Gambarelli D, Baret J (1969) Scapuloperoneal myopathies 14 cases including 8 with facial involvement. Sem Hop 45: $2678-2683$

3. Brooke MH (1986) Facioscapulohumeral dystrophy, Scapuloperonea dystrophy: A Clinician's View of Neuromuscular Diseases (2ndedn), Williams \& Wilkins, Baltimore.

4. Walton J, Gardner-Medwin D (1988) the facioscapulohumeral (FSH) muscular dystrophy, Autosomal dominant scapuloperoneal myopathy: Disorders of Voluntary Muscle (5thedn), Edinburg, Churchill Livingstone.

5. Bushby KMD (1997) Autosomal inherited muscular dystrophies, Emery and Rimoin's Principles and Practice of Medical Genetics, (3rdedn), New York: Churchill Livingstone.

6. Padberg GW (1998) Facioscapulohumeral muscular dystrophy, Neuromuscular disorders: clinical and molecular genetics, John Wiley \& Sons, Chichester.

7. Zeevaert B, Sadzot B, Deprez M, Wang FC (2002) Scapulo-peroneal weakness with tardive symptoms of facio-scapulo-humeral muscular dystrophy, connected to 4q35 chromosomal deletion. Rev Neurol (Paris) 158: 1210-1213.

8. Pou-Serradell A, Royo I, Lopez dr Munain A, Camano P (2004) Familial lateonset of shoulder and ankle dorsiflexors weakness related to $4 q 35$ chromosome deletion: Unusual phenotype of FSHD. Acta Myologica XXIII: 63.

9. Munsat TL, Serratrice G (1992) Facioscapulohumeral and scapuloperoneal syndromes, Handbook of Clinical Neurology, Myopathies, Amsterdam: Elselvier Science 161-177.

10. Amato AA, Russell JA (2008) Muscular dystrophies, Neuromuscular Disorders McGraw Hill, New York

11. Becker PE (1964) Myopathien, Humangenetik, Vol. III/I. Stuttgart: Thieme

12. Thomas PK, Schott GD, Morgan-Hughes JA (1975) Adult onset scapuloperoneal myopathy. J Neurol Neurosurg Psychiatry 38: 1008-1015.

13. Zellweger H, McCormick WF (1968) Scapuloperoneal dystrophy and scapuloperoneal atrophy. Helv Paediatr Acta 23: 643-649.

14. Carroll JE (1979) Facioscapulohumeral and scapuloperoneal syndromes, Handbook of Clinical Neurology, Diseases of Muscle, Amsterdam, NorthHolland.
15. Rowland LP (1996) Molecular genetics and clinical neurology, Allelic heterogeneity, locus heterogeneity, gene-defining mutations and clinical syndromes, Acta Cardiomiol.

16. Fisher J, Upadhyaya M (1997) Molecular genetics of facioscapulohumera muscular dystrophy (FSHD). Neuromuscul Disord 7: 55-62.

17. Orrell RW, Griggs RC (1999) Muscular dystrophies: Overview of clinical and molecular approaches, Muscle Diseases, Butterworth Heinemann, Boston.

18. Hawley RJ Jr, Schellinger D, O'Doherty DS (1984) Computed tomographic patterns of muscles in neuromuscular diseases. Arch Neurol 41: 383-387.

19. Horikawa H, Takahashi K, Nishio H, Mano Y, Takayanagi T (1992) $X$-ray computed tomographic scans of lower limb and trunk muscles in facioscapulohumeral muscular dystrophy. Rinsho Shinkeigaku 32: 1061-1066.

20. Olsen DB, Gideon P, Jeppesen TD, Vissing J (2006) Leg muscle involvement in facioscapulohumeral muscular dystrophy assessed by MRI. J Neurol 253 1437-1441.

21. Kan HE, Scheenen TW, Wohlgemuth M, Klomp DW, van Loosbroek Wagenmans I, et al. (2009) Quantitative MR imaging of individual muscle involvement in facioscapulohumeral muscular dystrophy. Neuromuscul Disord 19: 357-362.

22. Kazakov VM (1971) Facio-scapulo-humeral myodystrophy (clinic and genetic) thesis Leningrad, Pavlov Medical Institute.

23. Daniels L, Williams M, Worthingham C, (1956) Muscle testing, Techniques of manual examination. (2ndedn) Saunders, Philadelphia.

24. Kendall HO, Kendall FM (1949) Muscles, Testing and Function, Williams \& Wilkins, Baltimore.

25. Kazakov VM, Rudenko DI (1995) Clinical variability of facioscapulohumera muscular dystrophy in Russia. Muscle \& Nerve: S85-S95.

26. Kazakov V, Rudenko D, Katsev E, Sugita H (2000) Facioscapulolimb muscular dystrophy (facioscapuloperoneal form of FSHD) in Russian families. Phenotype/ genotype correlations. Acta Myologica XIX: 69-79.

27. Goto K, Lee JH, Matsuda C, Hirabayashi K, Kojo T, et al. (1995) DNA rearrangements in Japanese facioscapulohumeral muscular dystrophy patients: clinical correlations. Neuromuscul Disord 5: 201-208.

28. Jungbluth H, Davis MR, Müller C, Counsell S, Allsop J, et al. (2004) Magnetic resonance imaging of muscle in congenital myopathies associated with RYR1 mutations. Neuromuscul Disord 14: 785-790.

29. Kazakov VM, Rudenko DI, Skorometz AA (2008) Facioscapulohumera muscular dystrophy and it connected with facioscapuloperoneal muscular dystrophy 4q35-linked. History, clinical, genetics and differential diagnosis, Polytechnika St. Petersburg.

30. Kazakov V, Rudenko D, Kolynin V (2012) On nosological place of facioscapuloperoneal (or facioscapulolimb, type 2) 4q35-linked muscular dystrophy. Acta Myol 31: 161-162.

31. Kazakov VM, Bogorodinsky DK, Znoyko ZV, Skorometz AA (1974) The facioscapulo-limb (or the facioscapulohumeral) type of muscular dystrophy. Clinical and genetic study of 200 cases. Eur Neurol 11: 236-260.

32. Kazakov VM (1994) Affection of mimic muscles, simulating damage of the facial nerve in patients with facioscapulohumeral muscular dystrophy. Eur Arch Otorhinolaryngol .

33. Kazakov V (1995) History of the recognition and description of the Facioscapulohumeral muscular dystrophy (FSHD) and on the priorities of Duchenne, Erb, Landouzy and Dejerine. Acta Cardiomiol VII: 79-94

34. Kazakov V (2001) Why did the heated discussion arise between Erb and Landouzy-Dejerine concerning the priority in describing the facio-scapulohumeral muscular dystrophy and what is the main reason for this famous discussion? Neuromuscul Disord 11: 421.
This article was originally published in a special issue, Hereditary Disorders handled by Editor(s). Dr. X. Long Zheng, University of Pennsylvania, USA 